\title{
WAVE PROPAGATION BETWEEN BOOSTER LAMINATIONS INDUCED BY LONGITUDINAL MOTION OF BEAM
}

S. C. Snowdon

November 3, 1970

PURPOSE

To calculate the electromagnetic wave propagation in the crack between booster magnet laminations induced by longitudinal charge oscillations of the beam. The result is to be expressed in terms of a wave impedance at the iron boundary so that the effects of the propagation may be readily incorporated into beam dynamics calculations. Cylindrical geometry is assumed for simplicity.

RADIAL CRACK

An exact solution for an electromagnetic wave propagating radially in the geometry shown is to be found.

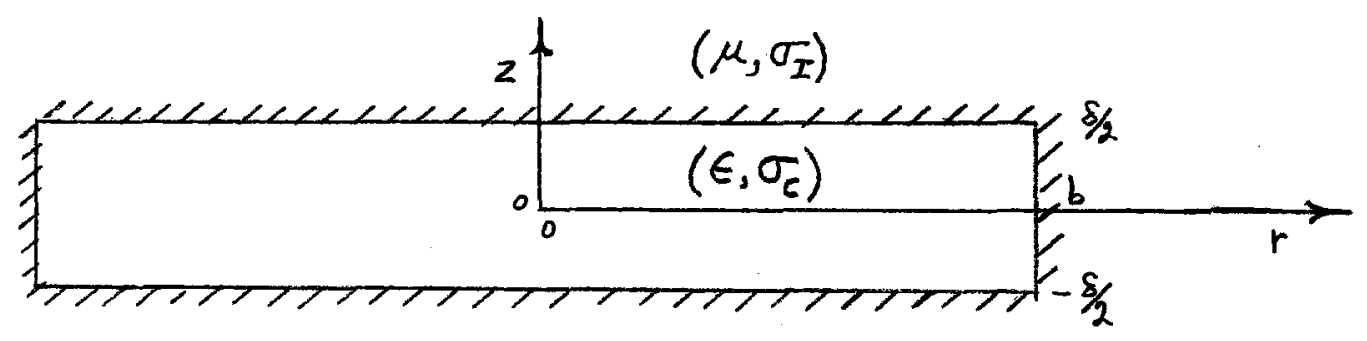

The transverse magnetic mode has its vector potential expressed as

$$
\vec{A}=\nabla \times \vec{U}
$$

where $\stackrel{>}{L}$ is the operator ${ }^{1}$ 


$$
\begin{gathered}
-2- \\
\mathrm{L}=\overrightarrow{\mathrm{k}} \times \overrightarrow{ },
\end{gathered}
$$$$
\text { TM-277 }
$$$$
0300
$$

and $\mathrm{k}$ is the unit vector along the $\mathrm{x}$-axis. Assuming a time variation of $e^{-i} \omega t$, one has

$$
\vec{A}=\vec{k} \nabla^{2} U-\nabla \frac{\partial U}{\partial z}, \quad \vec{B}=-\vec{L}^{2} \nabla^{2}
$$

For $U$, one has

$$
\nabla^{2} U_{c}+\left(\varepsilon \frac{\omega^{2}}{c^{2}}+\frac{4 \pi \sigma_{c} \omega}{c^{2}} i\right) U_{c}=0 \text { (crack, gaussian) }
$$

and

$$
\nabla^{2} U_{I}+\frac{4 \pi \mu \sigma_{I} \omega}{c^{2}} i U_{I}=0 . \text { (Iron, gaussian) }
$$

Thus no displacement current is assumed in the iron and unit permeability is assumed in the crack.

The following may be taken as solutions to Eqs. (4) and (5).

$$
\begin{aligned}
& U_{c}=c e^{-\lambda_{I} \frac{\delta}{2}} \operatorname{ch} \lambda_{c} z R_{o}(k r) \\
& U_{I}=D \operatorname{ch} \lambda_{c} \frac{\delta}{2} e^{-\lambda_{I} z} R_{o}(k r) \quad(z>0)
\end{aligned}
$$

where

$$
\mathrm{R}_{\mathrm{O}}(\mathrm{kr})=\mathrm{H}_{\mathrm{O}}{ }^{(2)}(\mathrm{kr}) \mathrm{H}_{\mathrm{O}}{ }^{(I)}(\mathrm{kb})-\mathrm{nH}_{\mathrm{O}}{ }^{(I)}(\mathrm{kr}) \mathrm{H}_{\mathrm{O}}{ }^{(2)}(\mathrm{kb}) \cdot(8)
$$

In Eq. (8) the functions are Hankel functions, $n$ is the reflection coefficient and $k$ is the radial propagation constant. In order to satisfy Eqs. (4) and (5)

$$
\lambda_{c}^{2}=k^{2}-\varepsilon \frac{\omega^{2}}{c^{2}}-\frac{4 \pi \sigma_{c} \omega}{c^{2}} i
$$




$$
\lambda_{I}^{2}=k^{2}-\frac{4 \pi \mu \sigma_{I} \omega}{c^{2}} i
$$

For $z>0$ the fields are

$$
\begin{aligned}
& E_{r c}=\frac{i \omega k \lambda_{c}}{c} c e^{-\lambda I \frac{\delta}{2}} \operatorname{sh} \lambda_{c} z R_{I}(k r) \\
& E_{z c}=-\frac{i \omega k^{2}}{c} c e^{-\lambda I \frac{\delta}{2}} \operatorname{ch} \lambda_{c} z R_{o}(k r) \\
& H_{\theta c}=-\frac{k \omega^{2}}{c^{2}}\left(\varepsilon+\frac{4 \pi \sigma_{c}}{\omega} i\right) c e^{-\lambda_{I} \frac{\delta}{2}} \operatorname{ch} \lambda_{c} z R_{I}(k r) \\
& E_{r I}=-\frac{i \omega k \lambda_{I}}{c} D \operatorname{ch} \lambda_{c} \frac{\delta}{2} e^{-\lambda_{I} z} R_{I}(k r) \\
& E_{z I}=-\frac{i \omega k^{2}}{c} D \operatorname{ch} \lambda_{c} \frac{\delta}{2} e^{-\lambda_{I} z} R_{o}(k r) \\
& H_{\theta I}=-\frac{4 \pi \sigma_{I} \omega k i}{c^{2}} D \operatorname{ch} \lambda_{c} \frac{\delta}{2} e^{-\lambda_{I} z} R_{I}(k r),
\end{aligned}
$$

where

$$
\mathrm{R}_{1}(\mathrm{kr})=\mathrm{H}_{1}{ }^{(2)}(\mathrm{kr}) \mathrm{H}_{\mathrm{O}}{ }^{(I)}(\mathrm{kb})-\mathrm{nH}_{1}{ }^{(1)}(\mathrm{kr}) \mathrm{H}_{\mathrm{O}}{ }^{(2)}(\mathrm{kb}) \cdot(17)
$$

Boundary conditions at $z=\delta / 2$ require continuity of $E_{r}$ and $H_{\theta}$. This gives

$$
\lambda_{c} C+\lambda_{I} \operatorname{coth}\left(\lambda_{c} \frac{\delta}{2}\right) D=0
$$




$$
\omega\left(\varepsilon+\frac{4 \pi \sigma_{c}}{\omega} i\right) \quad C-4 \pi i \sigma_{I} D=0,
$$

Equations (9), (10), (18), and (19) are solved simultaneously for the radial propagation constant $k$. The condition is

$$
\begin{aligned}
& \frac{4 \pi \sigma_{I}}{\omega} i \sqrt{\frac{c^{2} k^{2}}{\omega^{2}}-\varepsilon-\frac{4 \pi \sigma_{c}}{\omega} i} \\
& +\left(\varepsilon+\frac{4 \pi \sigma_{c}}{\omega} i\right) \sqrt{\frac{c^{2} k^{2}}{\omega^{2}}-\frac{4 \pi \mu \sigma_{I}}{\omega}} i \\
& \operatorname{coth}\left(\frac{\omega \delta}{2 c} \sqrt{\frac{c^{2} k^{2}}{\omega^{2}}-\varepsilon-\frac{4 \pi \sigma_{c}}{\omega}} i\right)=0
\end{aligned}
$$

The wave impedance in the crack will be calculated only for $z=0$ since the crack is assumed quite small. Then,

$$
Z(r)=-\frac{E_{z c}(r, 0)}{H_{\theta c}(r, 0)}
$$

To determine the reflection coefficient $n$, set the wave impedance in the crack at $r=b$ equal to the wave impedance for a plane wave in iron. Thus

$$
Z(b)=(I-i) \sqrt{\frac{\mu \omega}{8 \pi \sigma_{I}}} .
$$

Equations (12) and (13) then yield 


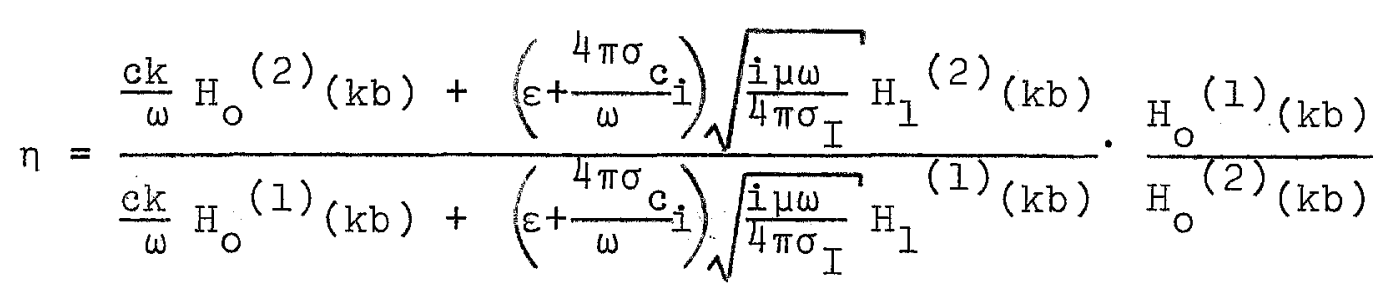

and

$$
z(a)=-\frac{i c k}{\varepsilon \omega+4 \pi \sigma_{c} \dot{i}} \cdot \frac{R_{0}(k a)}{R_{l}(k a)}
$$

RESULTS

Table 1 lists the permeability, permittivity and conductivity of materials that seem appropriate for booster laminations. The dielectric properties of core plating could not be obtained from the manufacturer. It has been assumed that they are close to a phosphate glass. Manufacturer's technical literature generally lists permeabilities as a function of frequency for the thickness of sheet manufactured. To obtain the incremental permeability $\left(\mu^{\prime}+i u^{\prime \prime}\right)$, one needs measurements on very small spheres in order to be free from flux exclusion by eddy currents at the higher frequencies. This data was taken from the FERROTRON ${ }^{2}$ design manual which lists the permeability of 3 micron diameter pure iron spheres uniformly imbedded in an insulating plastic binder. The permeability is sensibly constant up to $1000 \mathrm{NHz}$ indicating that the imaginary component is quite small. ARMCO Thin Electrical Steels ${ }^{3}$ indicate that the incremental permeability for $4 \mathrm{mil}$ 
sheet may be about 100 at $400 \mathrm{~Hz}$ for high excitation (bias), and low incremental induction. Combining the two bits of information, it seems reasonable to take the incremental permeability as 100 with no imaginary component in the frequency range of interest.

TABLE 1. Assumed Properties of Materials

$\begin{array}{lccccc} & \mu^{\prime} & \underline{\mu^{\prime \prime}} & \underline{\varepsilon^{\prime}} & \underline{\varepsilon^{\prime \prime}} & \frac{\sigma(\mathrm{Hz})}{4.5 \times 10^{16}} \\ \text { Iron } & 100 & - & - & - & 4 \times 10^{6} \\ \text { Core Plate } & - & - & - & - & 9 \times 10^{-2} \\ \text { Epoxy } & \\ \text { Phosphate Glass }^{4} & - & - & 5.2 & - & -\end{array}$

\begin{tabular}{|c|c|c|c|}
\hline$a(i n)$ & $b($ in $)$ & $D_{\text {lamin }}$ (in) & $\delta_{\text {crack }}($ in $)$ \\
\hline 750 & 6.000 & .0250 & .000375 \\
\hline
\end{tabular}

To obtain values of the propagation constant $k$ and impedances $Z$, the permeability of the iron was taken to be $\mu=100$, the permittivity of the crack was taken to be a mixture of $1 / 3$ that of epoxy with $2 / 3$ that of phosphate glass. The conductivity of iron is taken to be $20 \mu \mathrm{ohm}-\mathrm{cm}$ and that of the crack to be $10^{5} \mathrm{ohm}-\mathrm{cm}$.

Table 3 presents the results from the program CRACK. The propagation constant $k$ is given in units of $w / c$. In the impedance columns, first the real part is presented and then 
the imaginary. Gaussian units are employed, hence all impedances are dimensionless. By bore impedance, the impedance of Eq. (22) is meant. Crack impedance is the value given in Eq. (24). Guide impedance is series combination of bore impedance and crack impedance each taken in proportion to its relative thickness along the inner bore of the magnet. Figure $I$ presents a plot of the guide impedance as a function of frequency .

In particular, it is to be noted from Table 3 that the crack impedance introduces a large resistive component into the resultant guide impedance which would equal the bore impedance for zero crack width. 


\section{REFERENCES}

I S. C. Snowdon, Properties of the L-Operator, MURA Technical Note TN-506 (Oct. 19, 1964).

2 FERROTRON Design Manual, The Polymer Corp. Engineered Products Division, Reading, Penna. (1963); see also: GAF Carbonyl Iron Powders, General Aniline and Film Corporation, 140 W. 51 Street, New York, New York 10020 (1960).

3 ARMCO Thin Electrical Steels, Armco Steel Corporation, Midaletown, Ohio (1963).

4 Dielectric Materials and Applications, A. R. VonHippel, Editor, The MIT Press, Cambridge, Mass. (1954). 
RAOTAL CRACK PROPAGATION CONST ANT ANO IMPEDANCE

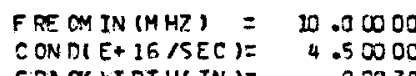
CRAOKWIDTH(IN) $=$
OUTERRADIIN) $=6.00000$

FREO (MHE)

P DO PAEATION SON ST ANT

10.000 20.000 30.000 40.000 50.000 60.000 T.0.000 90.000 90.90 110.000 113.000 130.000 140.000 140.000 150.000 170.000 190.000 200.000 210.000 220.000 233.000 240.00 250.000 260.000 270.000 280.000 290.000 300.000 310.000 320.000 $33 \mathrm{C.000}$ 340.000 350.000 360.000 370.000 390.00 390.900

410.000 410.000 430.090 430.000
440.000 450.000 450.000
480.000 470.000 480.000 490.000

\section{F RE OM AX (MHZ) $=500.00000$ \\ PER MEA ALITY $=100.00000$}

$\begin{array}{ll}\text { LAM IN TH ICKI TV })= & .02500 \\ \text { CRACK CONC IMH? I } & 9.00030\end{array}$

TR AN SVER SE MAGNE IIC MODF

BORE IM DE DANCE

CPACK IM DE DA NCE

$63047 E-01-6.08556 E-01$ $1.05945 E+00-8.19535 E-01$ 1. $4899 z+00-8.56175 E-0$ $8736 \%+00-6.43574 E-0$ . $99625 E+00-2.62832 E-01$ $8514 \mathrm{IE}+20$ 1. 90 9. $5 E-03$ $1.66334 E+005.93215 E=0$ $514735+00-6,75375 E-02$ 1. $531375+90-1.31855 E-01$ 1. $57681 E+00-1.70315 E-01$ 1. $63756 E+30-1.795255-0$ $1.6939 \mathrm{JE}+00-1.61$ QU $7 E-01$ $1.737435+00-1.241975-0$ 1. 7625 CE +00-7.5387 $1 E-02$ 1. $76879 E+00-2.67651 E-02$ 1. $76025 E+00$ 1. $56443 E+02$ $1.74296 E+004.74796 E-02$ $1.72232 E+306.23731 E-D 2$ $1.73420 E+00$ 8. $02658 E-02$ 1. EB $953 E+008.6102 \mathrm{BE}-02$ 1. $67959 E+0 \mathrm{~B}$ B. 8812 पE -32 $1.57398 E+00$ 9. $07756 E-02$ $1.8716 \pi+00$ 9. $36137 E-D 2$ 1.6713 GE + J O $9.82192 E-02$ $1.6718 \mathrm{JE}+0 \mathrm{O} \quad 1.04821 E-01$ $1.67198 E+701.13198 E-0$ $1.6711 \mathrm{BE}+0 \mathrm{O} 1.22835 E-01$ 1.6690 LE $+001.33097 E-01$ $1.6655 \mathrm{JE}$. 吅 $1.43365 \mathrm{E}-\mathrm{O}$ $1.66075 E+001.53133 E-\hat{U} 1$ $1.6550 \mathrm{EE}+0 \mathrm{O} \quad 1.62062 E-01$ 1.6488 IE + DO 1.6998 bE -01 $1.64234 E+001.76889 E-01$ 1. $63594 E+00 \quad 1.82871 E-01$ 1. $624010^{2} 00$ 1. $927555-01$

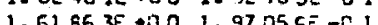
$1.513515+0022.011295-31$ $1.608900+002.051035$ $1.604405+002.030505-01$ $1.50004 E+502.13023 E-01$ $1.59573 E \rightarrow 002.15955 E-01$ $1.5914 \mathrm{LE}+50 \quad 2.20912 E-0$ $1.58706 E+032.24811 E-01$ 1. $58264 E+002.28 E 22 E-D$ 1. $57817 E+D D 2.32312 E-3$ $1.5736 \mathrm{GE}+002.35851 \mathrm{IE}-0$ $1.56912 E+002.39221 E-0$ $\begin{array}{lr}\text { NFREO } & 50 \\ A I R \text { DIELECT RI } & =4.75000\end{array}$

INNERRA OI IN $)=\begin{aligned} & 4.75000 \\ & .75000\end{aligned}$

GU DE IMPE OA NCE

an

9. $9587 \pi-03-915348 E-03$ 1. $588325-02-1.233735-02$ 2. $2295 \pi-02-1.29300 E-02$ 2. 8013 [F $-02-9.83104 E-03$ 2. 9859 IE $-02-4.24208 E-03$

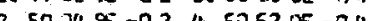
2. $33530=02$ प. 6062 वE -14

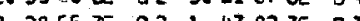
. 3144 ह5 $-02-204547105$

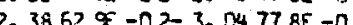
2. 4754 ह $-02-3.04778 E-03$

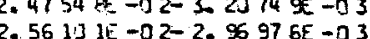
2.6275 ZE - D2-2. $43425 E-03$ . $2.6676 \pi \mathrm{C}-02-1.74134 E-03$
$2.6779 \mathscr{E}-02-1.03573 E-03$ 2. $56735 E-02-4.2869$ gE -04 $2.6437 \mathrm{lE}-02$ 2. $26512 \mathrm{ZE}-05$ 2. 81.58 एE $-02 \quad 3.12 \pi 72 E-04$ 2. 5901 U⿺ $=02$ 4. $7044 \pi-04$ 2. $57519-025.39032 E-04$ 2. $5572 X-025.61816 E-04$ 2. $55062 E-02$ 5. 7395 BE -04 2. 5468 \&E $-025259466 E-04$ 2.5507 ZE -02 6. $51285 E-04$ 2. 552 2 दE -02 7. $32997 E-174$ $2.554 J \pi-02$ 8. $4125 \mathrm{dE}-D$ 2. 5544 IE -02 9. 5841 9E $-D$ 2. 55,77 EE - 02 1. 1050 BE -0 2. 54 9 IE -02 1. $2420 \cong-0$ 2.5434 सE -02 1. $37195 E-03$ $2.53644 E-C 2 \quad 1.48965 E-03$ $2.5285 x-02 \quad 1.5927$ IE -03 2.5204 sE $-02 \quad 1.6309$ IE -03 2.5123 ZE -021.7556 9E -03 . 2. $4973 \mathrm{EL}-021.87522 E-03$ 2.4845 C -02 1. $97287 E-03$

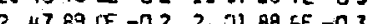
2. $46352 E-02$ 2. $06461 \varepsilon-03$ $2.463175-02 \quad 2.156$ 2. 45 ह3 $1 E-022.203085-03$ $2.4527 \mathrm{TE}-022.24870 \mathrm{OE}-03$ $2.44743 \bar{c}-022.29317 E-0$ 2.4423 UE $-022.33596 E-03$ $2.4364 E E-023.37655 E-D$ $2.430925-02$ 2. $41496 E-03$
.00000 .00000 .00000 .00000 .00030 .00000 .00000
.00000 .00000 $-00000$ .00000 .00360 00000 .00000 .00000

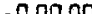
.00000 .00030 .00000 .00000 .0 .0000 .00000 .00000 .00000 .00000 .00000 .00000 .00000 .00000 .00000 - 00000 .00000 - 0 casas - cos - 00000 .0035 . 0 va jo -000 Da $-00000$ $-00000$ - 0 a o o .00300 


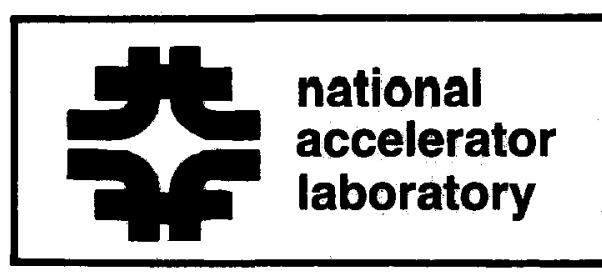

Author

S.C. Snowdon

Date $11 / 3 / 70$
Section

Section
Page

10 of 10

Category

Serial

Subject

RADIAL CRACK

TM-277

0300

$$
\begin{array}{lll}
\delta=.000375 \text { in } & \mu=100 & \sigma_{F e}=4.5 \times 10^{16} \mathrm{~Hz} \\
a=.750 \mathrm{in} & \epsilon=4.75 & \sigma_{\text {Diel }}=9 \times 10^{6} \mathrm{~Hz} \\
b=6.000 \mathrm{in} & &
\end{array}
$$

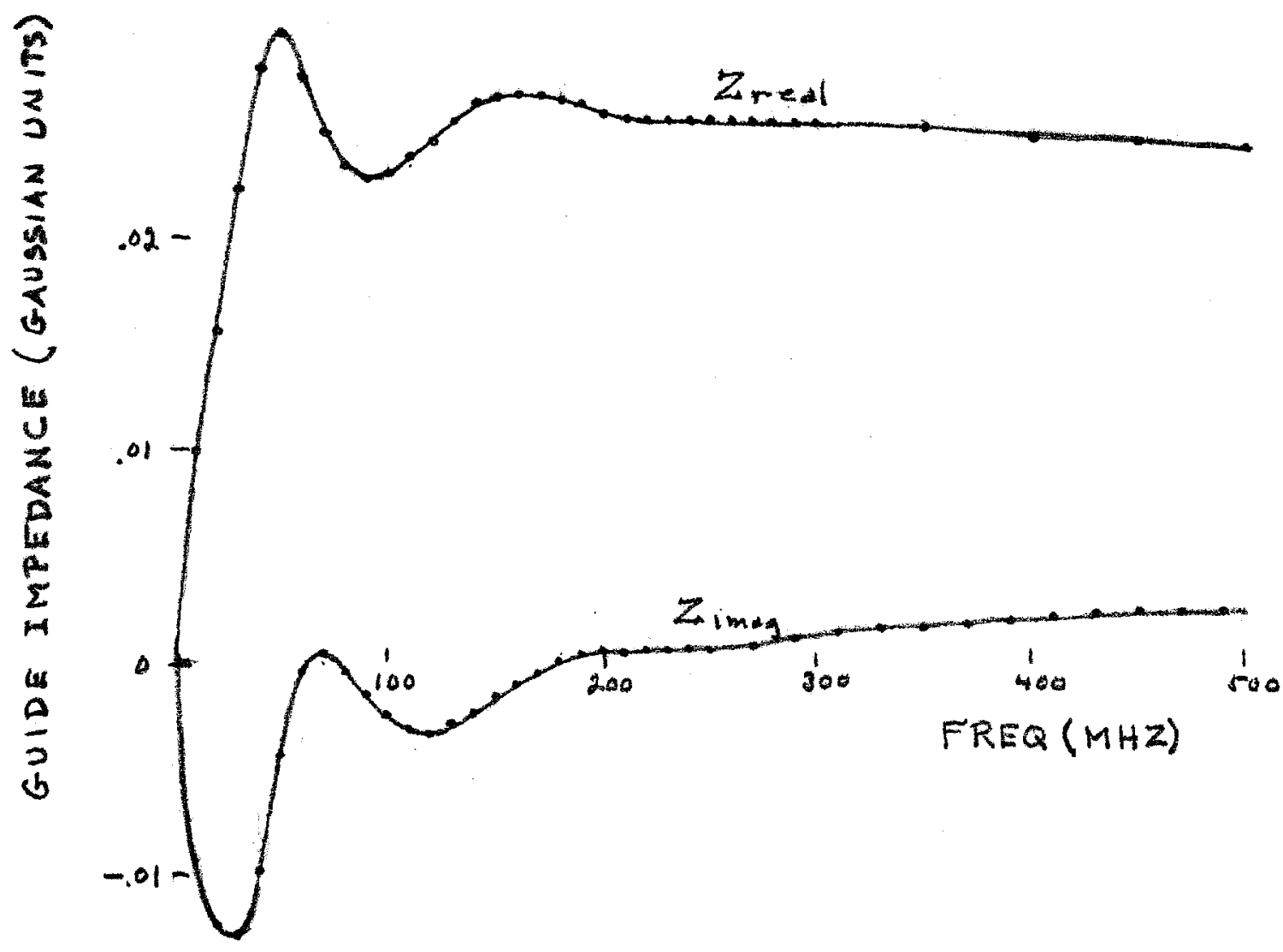

$-.02-$ 